\title{
Editorial
}

\section{COVID-19: A Global Health Concern}

\author{
Randeep Guleria $\quad$ Deep Narayan Srivastava²,3 \\ ${ }^{1}$ Director, All India Institute of Medical Sciences, New Delhi, India \\ ${ }^{2}$ Professor, Department of Radiodiagnosis and Interventional \\ Radiology, All India Institute of Medical Sciences, New Delhi, India \\ ${ }^{3}$ Honorary Secretary, National Academy of Medical Sciences (India), \\ New Delhi, India
}

Ann Natl Acad Med Sci (India):2020;2:53-54

Viral epidemics continue to emerge as a serious threat to public health. The past two decades have seen several viral epidemics, such as severe acute respiratory syndrome coronavirus (SARS-CoV) in 2002-2003, H1N1 influenza in 2009, and Middle East respiratory syndrome coronavirus (MERS-CoV) in 2012, which have caused great loss of human lives. This ongoing new pandemic caused by a novel Coronavirus (SARS-CoV-2), the Coronavirus disease 2019 (COVID-19), emerged as an acute respiratory disease in December 2019 in Wuhan city of Hubei province, China, and spread globally.

On January 12, 2020, WHO confirmed the genetic sequence of the novel Coronavirus shared by Chinese scientists, who isolated it on January 07, 2020.2 On January 30, 2020 , as per the international health regulations (IHR, 2005), the outbreak was declared by the WHO as a public health emergency of international concern (PHEIC). On March 12, 2020, WHO declared COVID-19 to be a pandemic.

Over the last 4 months, this pandemic has marched relentlessly and has penetrated more than 216 countries globally. As of today (June 17, 2020), COVID-19 outbreak data globally, as per WHO, is 804,3487 cases and 439,487 deaths, ${ }^{3}$ and in India, as per Ministry of Health and Family Welfare, Government of India, there are 155,227 active cases, 186,934 have been cured/discharged with 11,903 deaths. ${ }^{4}$ This pandemic has reminded scientists of the 1918 flu pandemic. India had the largest number of deaths in any single country at that time (10-20 million) and the global death toll was 50 to 100 million. ${ }^{5}$ Things have changed significantly over the past 100 years, but the basic infection control practices have remained the same. We need to learn from history and ensure that the same mistakes are not committed again. For example, after the lockdown was lifted in 1918, people did not observe social distancing and came out and even indulged in parties. This allowed the virus to spread again,

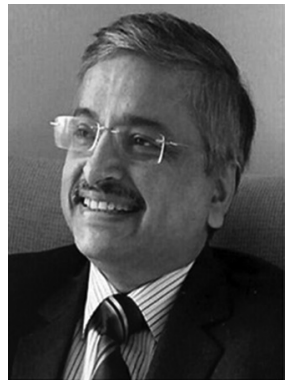

Randeep Guleria

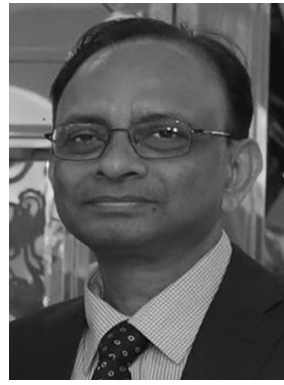

Deep N. Srivastava and the second wave killed more people than the first one. We therefore need to be more vigilant in enforcing infection control measures in the coming months.

Various measures have been taken globally to manage and check the spread of disease at community levels by developing preventive and therapeutic strategies. Facilities such as 24-hour flu screening OPDs with a system of triage for quick examination and treatment have been set up. Some hospitals were expressly designated for COVID-19 patients. An entire system of COVID care centers (as isolation facility for stable patients), COVID care hospitals (for patients needing oxygen and comorbidity management), and COVID ICUs (for critical care) were set up at a district level to meet the possible increasing demand of cases. In order to confirm the diagnosis and increase the capacity of conducting more molecular tests (RT-PCR), new facilities such as molecular laboratories were set up and medical colleges were upgraded. Public messages and videos about prevention of disease by wearing masks, using hand hygiene, observing cough etiquette, social distancing, and avoiding crowded areas were spread by various print and electronic media. International airports initially placed the screening mechanism to detect infected people for quarantine; later, international flights were suspended, and international boundaries were sealed in various countries. In India complete lockdown was imposed for 3 weeks on March 25, 2020, after a 14-hour voluntary public curfew on March 22, 2020.6,7 The aim was to slow down the growth rate of the pandemic. It was further extended until May 03 (phase 2), May 17 (phase 3) and May 31 (phase 4). On May 30, 2020, the lockdown was further extended till June 30 in containment zones. The rest of the areas have resumed various services in a phased manner from June 08 onward, a process which has been termed as "unlock." 8,9
DOI https://doi.org/

10.1055/s-0040-1713959 ISSN 0379-038X.
(C)2020 National Academy of Medical Sciences (India)
License terms

(요 (1) $\Theta \circledast$ 
Some people are facing undue stigma linked to the disease and its treatment. This causes delay in treatment and may increase mortality as patients report late to the hospital with advanced respiratory failure. ${ }^{10}$ Healthcare workers and supporting staff are bearing enormous work pressure, risk of infection, and also the violent behavior of patients and public in general due to the stigma related to the disease. Clear, coordinated management guidelines need to be communicated consistently to healthcare professionals as well as to the public to avoid unnecessary fear and anxiety. ${ }^{11}$

This viral outbreak has not only challenged the medical and public health infrastructure of countries but also the economy at large. The potential benefits from the steps taken to contain the disease compared with economic losses will be debated for years. ${ }^{12}$

It is critical to improve international surveillance, cooperation, coordination, and communication about this pandemic and to be even better prepared to respond to future public health threats. We also need to develop some comprehensive strategies both at the national and international level to combat future outbreaks of viruses and other pathogens of zoonotic origin.

Since knowledge about COVID-19 is rapidly evolving, we need to update ourselves regularly. In this issue, the latest research progress in the fields of epidemiology, immunepathophysiology, clinical management and scientific advancements to uncover the mystery of the molecular mechanism of viral entry and replication, which form the basis of future research on developing targeted antiviral drugs and vaccine, will be covered.

Conflict of Interest

None declared.

\section{References}

1 Wang C, Horby P W, Hayden F G, Gao G F.. A novel corona virus outbreak of global health concern. The Lancet2020;395(10223): 470-473

2 Lu R, Zhao X, Li J, et al. Genomic characterisation and epidemiology of 2019 novel coronavirus: implications for virus origins and receptor binding. The Lancet 2020;395(10224) :565-574

3 WHO. Corona Virus Disease (COVID-19) Outbreak Situation. Available at: https://www.WHO.int/home/emergencies/ diseases/coronavirus. Accessed June 17, 2020

4 MOHFW. COVID-19 India. Available at: https://www.mohfw. gov.in/. Accessed June 17, 2020

5 Kant L, Guleria R. Pandemic flu, 1918: after hundred years, India is as vulnerable. Indian J Med Res 2018;147(3):221-224

6 Jeffrey G, Kai S. Modi Orders 3-week Total Lockdown for All 1.3 Billion Indians. Available at: www.nytimes.com. Accessed June 17, 2020

7 COVID-19. Lockdown across India, in Line with WHO Guidance. Available at: www.news.un.org. Accessed June 17, 2020

8 Hindustan Times. After Covid-19 Lockdown, Plan to Unlock India in Phases. Available at: www.hindustantimes.com. Accessed June 17, 2020

9 The Guardian. India Extends Lockdown in 'High-Risk' Zones. Available at: www.the guardian.com. Accessed June 17, 2020

10 India Today. Covid-19 Stigma is More Serious Challenge than Disease, Warns AIIMS Doc Guleria. Available at: https://www. indiatoday.in/india/story/covid-19-is-not-a-serious-disease-aiims-chief-dr-randeep-guleria-1670221-2020-04-23. Accessed June 17, 2020

11 Varghese GM, John R. COVID-19 in India: moving from containment to mitigation. Indian J Med Res 2020;151(2\&3): 136-139

$12 \mathrm{Wu} \mathrm{Z,} \mathrm{McGoogan} \mathrm{JM.} \mathrm{Characteristics} \mathrm{of} \mathrm{and} \mathrm{important} \mathrm{les-}$ sons from the Coronavirus Disease 2019 (COVID-19) outbreak in China: summary of a report of 72,314 cases from the Chinese center for disease control and prevention. JAMA 2020;323(13):1239-1242 